\title{
WELLNESS SYNDROME
}

\author{
Evgeniya Vladeva
}

\author{
Department of Physiotherapy, Rehabilitation, Thalassotherapy and Occupational \\ Diseases, Faculty of Public Health, Medical University of Varna, Bulgaria
}

\begin{abstract}
INTRODUCTION: Wellness is a lifestyle choice based on the holistic approach to health. In this century, and during the last decade in particular, wellness centers and wellness procedures have become quite popular. And just like any trend, the one related to wellness may lead to extremes. In this specific case, the extremes are defined as a „wellness syndrome“ - an obsession with a healthy lifestyle. The maximization of the efforts to achieve wellness can turn against us and make us feel bad making us isolate ourselves from the rest. The wellness syndrome leads to a search for the perfect diet, turns us into corporate athletes, chasing our own selves and monitoring each aspect of our everyday life. This is a world where feeling well is indistinguishable from being well.

AIM: This article is an attempt to separate the aspiration toward wellness from the other extreme - an obsession with psycho-emotional techniques of mastering stress or a fixation with different esthetic procedures (which, in addition to the beneficial desired effect, may have side effects, if overused). One such condition distances the individuals from the real world and society, limits them to a tiny circle of other people, which automatically impairs at least one aspect of their wellness - the social one.
\end{abstract}

MATERIALS AND METHODS: Articles and scientific publications related to the topic were searched in the PubMed database and Google Scholar. Articles published in the last decade were included in the review. The search was conducted with a list of keywords used also in different combinations. These were: "health", “wellness”, “wellness syndrome”, “orthorexia”, “wellbeing”, „esthetics“. The article draws on the work by Carl Cederström and André Spicer titled „Wellness Syndrome“, which currently provides the most detailed information on the "wellness syndrome".

Special attention is paid to orthorexia as one of the most common cases of overstepping the border between a healthy diet and the maniacal obsessive idea of consuming healthy food, which may develop into a disease process.

CONCLUSION: The basic knowledge and skills by which physical therapists should encourage health and wellness in their patients and clients are a topic included in university curricula. However, the provided information is predominantly theoretical. The increased attention to applying theory and the development

Address for correspondence:

Evgenia Petrova Vladeva, $M D, P h D$,

Department of Physiotherapy, Rehabilitation,

Thalassotherapy and Occupational Diseases

St. Marina Univesity Hospital of Varna

1 Hr. Smirnenski Blvd

9000 Varna

e-mail: jeni.vladeva@gmail.com

Received: July 3, 2019

Accepted: September 19, 2019 of clinical competence into skills, such as consultation, change in healthy behavior and motivation (e.g. physical activity, diet and maintaining normal weight, smoking cessation, sleep hygiene, and stress management), will improve the ability of physiotherapists to include adequate models of improving the health and wellness of their patients and clients.

Keywords: health, wellness, wellness syndrome, orthorexia 


\section{INTRODUCTION}

Wellness is a lifestyle choice based on the holistic approach to health. In this century, and during the last decade in particular, wellness centers and wellness procedures have become quite popular. And just like any trend, the one related to wellness may lead to extremes. In this specific case, the extremes are defined as a "wellness syndrome" - an obsession with a healthy lifestyle. The maximization of the effort to achieve wellness can turn against us and make us feel bad making us isolate ourselves from the rest. The wellness syndrome leads to a search for the perfect diet, turns us into corporate athletes, chasing our own selves and monitoring each part of our everyday life. This is a world where feeling well is indistinguishable from being well.

\section{AIM}

The aim of this article is to separate the aspiration toward wellness from the other extreme - an obsession with psycho-emotional techniques of mastering stress or a fixation with different esthetic procedures (which, in addition to the beneficial desired effect, may have side effects, if overused). One such condition distances the individuals from the real world and society, limits them to a tiny circle of other people, which automatically impairs at least one aspect of their wellness - the social one.

\section{MATERIALS AND METHODS}

Articles and scientific publications related to the topic were searched in PubMed database and Google scholar. Articles published in the last decade were included in the review. The search was conducted with a list of keywords used also in different combinations. These were: "health", "wellness", "wellness syndrome”, “orthorexia”, "wellbeing”, „esthetics“. The article draws on the work by Carl Cederström and André Spicer titled „Wellness Syndrome “, which currently provides the most detailed information on the "wellness syndrome".

Special attention is paid to orthorexia as one of the most common cases of overstepping the border between a healthy diet and the maniacal obsessive idea of consuming healthy food, which may develop into a disease process.

\section{Wellness}

Concepts and Definitions of Health and

Before considering any impairment, first, it is important to provide a definition of wellness. There is no exact definition, which is used universally. Wellness is a generalized term describing the healthy balance of mind, body, and spirit, which results in an inner feeling of well-being. All wellness strategies aim at proper management of everyday life in order to achieve a state of physical and spiritual balance - a healthy body and a positive state of mind.

And it is not a question of covering the idea of no illness, but of emphasizing each individual's sense of well-being. Wellness is a lifestyle choice based on the holistic approach to life. In this century, and during the last decade in particular, wellness centers and wellness procedures have become extremely popular. Just like any other trend, the one related to wellness may lead to extremes. In this particular case, the extremes are defined as "wellness syndrome" - an obsession with a healthy lifestyle.

Physical therapists are in an ideal position to encourage their patients and clients to maintain their health and well-being (1). These professionals can work to decrease the risk factors levels and prevent and treat chronic conditions by providing patients and clients with information, prescribing physical activity and exercises, and by conducting non-invasive interventions consistent with the biopsychosocial paradigm $(2,3)$. Despite this, patients and clients often do not manage to acknowledge the role of the physiotherapist in maintaining good health.

The Word Health Organization (WHO) has developed the most widely cited definition of health: "state of complete physical, mental and social wellbeing and not merely the absence of disease or infirmity" (4). This definition, dating back to the 1940 s, states that health is more than physical health and the efforts toward its improvement should be comprehensive.

The concepts of health and wellness are a subject of various interpretations and views.

Wellness is defined as "a feeling that one lives in a way allowing the experiencing of constant, balanced growth in the physical, mental, emotional, intellectual, social and psychological dimensions of human existence“ $(5,6)$. Wellness can be positive or 
healthy, multidimensional, interactive and subjective (based on perceptions) (5,7-12).

According to Mayers, Sweeny and Witmer, wellness represents „a way of life oriented towards optimal health and well-being in which body, mind and spirit are integrated" (13). Smith and Kelly accept the following definition of wellness: „a healthy balance of mind, body and spirit and an overall feeling of well-being" (14). The nature of wellness includes specific fields of influence - normal function- ing of the human body, social communications, intellectual growth, emotional status and mind, and professional development. The wellness concept is inspired by philosophies, such as Ayurveda, Feng Shui, Reiki, etc.

In the literature there are many suggestions of "measuring" wellness, which encompass well-being, including the physical, emotional, intellectual, psychological, spiritual, and social spheres of life (Table 1) (5).

Table 1. Definition of measuring wellness (5). Interactive guide to physical therapist practice. American Physical Therapy Association. Published 2003. Available at: http://guidetoptpractice.apta.org/

\begin{tabular}{|c|c|c|}
\hline $\begin{array}{l}\text { Dimension of } \\
\text { Wellness }\end{array}$ & Definition & $\begin{array}{l}\text { Questions to Consider with Patients and } \\
\text { Clients }\end{array}$ \\
\hline Emotional & $\begin{array}{l}\text { The possession of a secure sense of } \\
\text { self-identity and a positive sense of } \\
\text { self-regard }\end{array}$ & $\begin{array}{l}\text { Is the patient or client self-aware? } \\
\text { Is the patient or client self-confident and } \\
\text { secure? } \\
\text { Does the patient or client use negative self-talk? }\end{array}$ \\
\hline Intellectual & $\begin{array}{l}\text { The perception that one is internally } \\
\text { energized by the appropriate amount } \\
\text { of intellectually stimulating activity }\end{array}$ & $\begin{array}{l}\text { Is the patient or client interested in the patholo- } \\
\text { gy of his or her illness or disease? } \\
\text { Does the patient or client ask questions and } \\
\text { demonstrate curiosity about his or her health } \\
\text { status? } \\
\text { Does the patient or client engage in intellectual- } \\
\text { ly stimulating activities? }\end{array}$ \\
\hline Physical & $\begin{array}{l}\text { Positive perceptions and expectancies } \\
\text { of physical health }\end{array}$ & $\begin{array}{l}\text { Does the patient or client demonstrate interest } \\
\text { in improving his or her physical health? } \\
\text { How does the patient or client rate overall } \\
\text { health (excellent, good, fair, poor)? }\end{array}$ \\
\hline Psychological & $\begin{array}{l}\text { A general perception that one will ex- } \\
\text { perience positive outcomes to the } \\
\text { events and circumstances of life }\end{array}$ & $\begin{array}{l}\text { Is the patient or client optimistic or pessimistic? } \\
\text { Does the patient or client have negative } \\
\text { thoughts or feelings about the ability to recover } \\
\text { or reach a level of better health? }\end{array}$ \\
\hline Social & $\begin{array}{l}\text { The perception that family or friends } \\
\text { are available in times of need, and the } \\
\text { perception that one is a valued sup- } \\
\text { port provider }\end{array}$ & $\begin{array}{l}\text { Does the patient or client have family and } \\
\text { friends to provide support? } \\
\text { Does the patient or client provide support to } \\
\text { others? }\end{array}$ \\
\hline Spiritual & $\begin{array}{l}\text { A positive sense of meaning and pur- } \\
\text { pose in life }\end{array}$ & $\begin{array}{l}\text { Does the patient or client have goals and ambi- } \\
\text { tions beyond himself or herself? } \\
\text { Does the patient or client demonstrate a belief } \\
\text { in something beyond himself or herself? } \\
\text { Is the patient or client involved in a church or } \\
\text { religion? }\end{array}$ \\
\hline
\end{tabular}


Despite the fact that many authors do no differentiate between health and wellness (7), there are others that separate the terms, stating that health is a wider concept $(5,8)$, and still others believe that wellness is more comprehensive (9). Using the definitions, we can conclude that both terms are multidimensional and each one influences the other. A person can be physically healthy, while at the same time being obsessed with something, ignoring relationships, mental and intellectual activities. The opposite is also possible. A person can be physically impaired but at the same time - with strong will and mentally healthy, like many of the patients and clients who are treated by physiotherapists for chronic diseases and impairments. These are patients who live a life, which is productive and full of meaning. The important take-home message for physical therapists and other health care providers is that both health and wellness encompass more than physical health, and efforts that focus primarily on physical health (e. g., physical activity, weight management, nutrition), although important, fail to recognize the influence of the other dimensions to overall well-being (18).

The wellness philosophy aims to unite the wisdom of humankind and apply it in everyday life. Achieving the overall well-being of the human mind and body requires a complex approach, which combines different techniques, procedures and therapeutic practices, together with emotional and spiritual exercises. The final goal of these therapies and procedures is to create a feeling of content and calmness for the individual. The definition given by Mueller and Kaufmann describes wellness tourism as "sum of all relationships and phenomena resulting from a change of location and residence by people in order to preserve or promote their health" (15).

Having in mind that the term wellness is very wide-ranging, the "wellness syndrome" must be observed in every aspect, for example, in obsessing over psycho-emotional techniques of stress management or fixating on different esthetic procedures (which, in addition to the beneficial desired effect, lead to side effects when overused). One such state, which distances individuals from the real world and society, leaves them in a very limited circle of people, which automatically impairs at least one aspect of wellness - the social well-being.

\section{Wellness Syndrome and Orthorexia}

All specialists recommend a healthy diet as a preventive measure against dozens, or even hundreds of diseases, which pose a danger to health. However, the complete obsession with the avoidance of pizzas, chips and canned food can turn into a disease called orthorexia nervosa.

The term was introduced in 1997 by Dr. Steven Bratman from Colorado. He describes an eating disorder characterized by an obsession with a healthy diet, which, if it turns into a fixation, may lead to malnutrition, psychiatric disorder, and even death. The term comes from the Greek words orthos (proper, right) and orexis (appetite). Dr. Bratman presents orthorexia as an obsessive idea about healthy eating or more like what the sufferers believe is healthy for them. They may avoid specific foods, for example, those containing fats, preservatives, animal products or any other ingredients, which they deem as harmful. In some cases, this fixation might develop into a disease and result in severe malnutrition, even starving to death (16).

According to Dr. Bratman orthorexia is observed most frequently among the followers of specific diets, for example, those following a raw food diet, with the health-related consequences being just as serious as the anorexia-related ones. However, the motivation is different. Whereas the anorexic individual would like to shed more weight, the idea of the orthorexic person is to feel cleaner, healthier and more natural.

Dr. Bratman used to suffer from orthorexia himself. He has dedicated many years to alternative medicine and a healthy lifestyle. For a long time, he adhered to the principles of a healthy diet, but at certain point felt that this was turning into an obsession and he was becoming addicted to it. Initially, he stopped eating meat, then - dairy products, in the end he consumed only plant food, and only if it was freshly picked. Following a healthy diet became his fixation and he could not think about anything else. He noticed that this had an impact on his contacts with the surrounding world. Trying to stop, Dr. Bratman discovered that it was impossible, that he had gone too far. Then, he described all this as orthorexia - an eating disorder with the same intensity, severity, and level of risk as anorexia and bulimia (16). 
Two studies on the problem define orthorexia nervosa as "an obsessive compulsive idea about healthy food.” People suffering from it often exhibit the same symptoms as in an obsessive compulsive disorder. In his book Health Food Junkies (1997), Dr. Bratman provides several questions, which allow people to determine whether they have any of the symptoms of an eating disorder, such as: "Does your way of eating differ from that of your family?", "Do you feel guilty if you eat something not allowed in your diet?", "Are you more interested in the healthy components in your food than in its taste?", "Does your diet isolate you socially?", "Do you plan your menu for the day after?". "We all aim to eat healthily, but when this normal behavior turns into an obsession, which is harmful to health, then we talk about orthorexia," Dr. Bratman explains (17).

Orthorexics often have an extreme attitude toward different foods. For them, preserved foods are "dangerous", and the industrially processed ones are "artificial". All colorants, additives, sweeteners, and all types of "Es" should never be included in the menu. The only foods that are good enough to be on their table are with an organic certificate. Those suffering from this eating disorder are capable of not eating anything for a long period of time if they cannot find any food that can be classified as healthy. They are filled with an extreme sense of guilt if they consume something they consider unhealthy (21).

Orthorexics are not obsessed with their weight. Their obsession is with the type of the products, not with the weight and amount of food as in anorexics and bulimics. However, this fixation itself makes them vulnerable to anorexia, because the limitation of nutrients leads to extreme weight loss (22).

Orthorexia may also lead to serious health problems. For example, the lack of fats in the organism inhibits the absorption of fat-soluble vitamins. The absorption of minerals and microelements is impaired. Without meat, the iron and protein levels might decrease significantly, especially without the consumption of iron- and protein-rich plant foods. The exclusion of basic nutrients from the diet can lead to anemia, and vitamin, calcium and energy deficiency (17).

As with anorexia, the treatment of the psychological problems related to the orthorexia is more difficult than healing the body. Orthorexia, bulimia, and anorexia are psychiatric conditions, which are often interrelated. There are cases where a person goes through all of them before being cured with the help of specialists or succumbing to the disease.

Carl Cederström and André Spicer and Their Wellness Syndrome

In our times, the idea of wellness is definitely missing something. In order to attain wellness, a person should eat properly, sleep enough, exercise regularly and have the right social and professional development. This hegemonic idea of wellness, however, contains no intellectual main point according to the authors. In the past, people speaking Latin used to say „mens sana in corpore sano," which means that the healthy mind is as important as the healthy body, and sometimes the whole purpose of a person having a healthy body is to have a healthy mind. But we live in times where the contemporary idea of wellness is the opposite of deeper thinking. Instead of this, we are encouraged to become happy but dumb athletes (18).

The authors indicate that American university students are required to sign "wellness contracts" with their university according to which they promise to "maintain a lifestyle without alcohol and drugs." The rules of corporate well-being now span from a ban of smoking at the workplace to a ban of smokers altogether, even if they only smoke at home. At the same time, there are offices that offer desks with treadmills and implement different approaches to ensure the well-being of their employees.

Discussing the employees at Amazon warehouses, the authors note: "Although they are in a precarious situation, they are required to hide these feelings and project a confident, upbeat, employable self." And what of the followers of the "quantified self" movement, who use various devices and applications to track not only their sleep but each step as well? It is easy to dismiss this as technologically enabled narcissism, but the authors offer a more sympathetic and troubling diagnosis: perhaps such people have just "given up on their personal project, and have willingly handed over their bodies to the larger cause of productivity" (23).

"Our concern," the authors explain as a whole, "is about the way in which the perception of wellness 
has become an ideology." In fact, the authors note that the wellness ideology has been identified with the controversial movement in psychology called "positive thinking" - the twin assumptions that you can be whatever you want to be and if something bad happens to you, it would be nobody else's fault but yours (18).

This way the apparent optimism of the social encouragement of wellness hides a brutal libertarian lack of compassion. But the authors would like to know: "Where does our preoccupation with our own wellness leave the rest of the population, who have an acute shortage of organic smoothies, diet apps and yoga instructors?"

Maybe we need a new attitude. Even if we are not completely brainwashed by the wellness syndrome, it is still easy to find a person, seduced by a certain aspect of the wellness project, who would say that he wants to be better in one way or another, and especially if wellness is defined as encompassing also our intellectual powers and behavior toward others. It is also true that when someone asks how we are and we are inclined to give a positive reply, we can honestly say "Very well, thank you!" Without a doubt these authors will agree that there is nothing bad in being well or wanting to be well. But as their deeply humane and persuasive book shows, being told to be well is a completely different matter. A society where wellness is mandatory is a sick one (18).

\section{CONCLUSION}

Because of the limited amount of information, which can be found on the problem about the wellness syndrome, it is very difficult to have a discussion based on facts. In the future, a sociological survey can be conducted in Bulgaria. It may provide answers to many questions from the point of view of our society.

It is a well-known fact that the healthy mind has a healthy body and both are interrelated. Every selfloving and self-respecting person looks for ways to achieve this balance between body and mind in order to be an adequate member of society. The problem with the obsession with healthy living is advancing further and further today. There are more people who listen when a healthy lifestyle is mentioned, but they do not pay attention when it is said that ev- erything should be within reason and they still go to extremes.

In conclusion it could only be said that balance is the key to good health, balance is also exclusively individual and different for every person. It is important for everyone to find this individual balance in order to discover his/her own wellness.

The main knowledge and skills by which physical therapists should encourage health and wellness in their patients and clients are a topic included in the curricula at the initial levels. The provided information, however, is predominantly theoretical (19). The increased attention to applying theory and the development of clinical competence into skills, such as consultation, change in healthy behavior and motivation (e.g. physical activity, diet and maintaining normal weight, smoking cessation, sleep hygiene, and stress management), will improve the ability of physiotherapists to include adequate models of improving the health and wellness of their patients and clients $(19,20)$.

\section{REFERENCES}

1. American Physical Therapy Association. Interactive guide to physical therapist practice; 2003. Available at: http://guidetoptpractice.apta.org/. Accessed April 6, 2014.

2. Dean E, de Andrade AD, O’Donoghue G, Skinner M, Umereh G, Beenen P, et al. The Second Physical Therapy Summit on Global Health: developing an action plan to promote health in daily practice and reduce the burden of non-communicable diseases. Physiother Theory Pract. 2014;30(4):261-75. doi: 10.3109/09593985.2013.856977.

3. Dean E. Physical therapy in the 21st century (part I): toward practice informed by epidemiology and the crisis of lifestyle conditions. Physiother Theory Pract. 2009; 25(5-6):330-53. doi: $10.1080 / 09593980802668027$.

4. Preamble to the Constitution of the World Health Organization as adopted by the International Health Conference, New York, June 19-22, 1946; signed on July 22, 1946, by the representatives of 61 states (Official Records of the World Health Organization, no. 2, p. 100) and entered into force on April 7, 1948. Available at: http://www.who.int/ about/definition/en/print.html.

5. Adams T, Bezner J, Steinhardt M. The conceptualization and measurement of perceived well- 
ness: integrating balance across and within dimensions. Am J Health Promot. 1997; 11(3):208-18. doi: 10.4278/0890-1171-11.3.208.

6. Adams TB, Bezner JR, Drabbs ME, Zambarano RJ, Steinhardt MA. Conceptualization and measurement of the spiritual and psychological dimensions of wellness in a college population. J Am Coll Health. 2000;48(4):165-73. doi: $10.1080 / 07448480009595692$.

7. Myers JE, Sweeney TJ, Witmer M. The wheel of wellness counseling for wellness: a holistic model for treatment planning. J Counsel Dev. 2000; 78(3):251-66. doi: 10.1002/j.1556-6676.2000. tb01906.x.

8. Corbin CB, Pangrazi RP. Toward a uniform definition of wellness: a commentary. Pres Counc Phys Fit Sport Res Dig. 2001; 3:1-8.

9. Thompson CR, ed. Prevention Practice. A Physical Therapist's Guide to Health, Fitness, and Wellness. Thorofare, NJ: Slack Inc; 2007.

10. Anspaugh DJ, Hamrick MH, Rosato FD. Wellness Concepts and Applications. St Louis, MO: Mosby; 1994.

11. Goodgold S. Wellness promotion beliefs and practices of pediatric physical therapists. Pediatr Phys Ther. 2005; 17(2):148-57. doi: 10.1097/01. pep.0000163076.97049.a8.

12. Roscoe LJ. Wellness: a review of theory and measurement for counselors. J Counsel Dev. 2009; 87:216-26. doi:10.1002/j.1556-6678.2009.tb00570.x.

13. Mayers J, Sweeny J, Witmer J. The Wheel of Wellness counseling for wellness: A holistic model for treatment planning. Wiley Online Library; 2011.
14. Smith M, Kelly S. Wellness Tourism. Tour Recreat Res. 2016;31(1):1-4. doi:10.1080/02508281.2006.1 1081241.

15. Mueller H, Kaufmann EL. Wellness tourism: Market analysis of a special health tourism segment and implications for the hotel industry. J Vacat Mark. 2001; 7(1):5-17. doi:10.1177/135676670100700101.

16. Dunn T, Bratman S. On orthorexia nervosa: A review of the literature and proposed diagnostic criteria. Eat Behav. 2016;21:11-7. doi: 10.1016/j. eatbeh.2015.12.006.

17. Bratman S. Orthorexia vs. theories of healthy eating. Springer; 2017.

18. Cederström C, Spicer A. The wellness syndrome. Polity Press, UK; 2015.

19. Bodner ME, Rhodes RE, Miller WC, Dean E. Benchmarking curriculum content in entry-level health professional education with special reference to health promotion practice in physical therapy: a multi-institutional international study. Adv Health Sci Educ Theory Pract. 2013; 18(4):645-57. doi: 10.1007/s10459-012-9404-X.

20. Lorish C, Gale JR. Facilitating behavior change: strategies for education and practice. J Phys Ther Educ. 1999; 13:31-7.

21. http://binar.bg/29038/ ortoreksiya-zdravoslovnata-maniya/

22. https://www.bb-team.org/articles/4040_ortoreksiya

23. https://www.theguardian.com/books/2015/jan/22/ the-wellness-syndrome-carl-cederstrom-andrespicer-persuasive-diagnosis 